\title{
BIOMETRIA E QUALIDADE FISIOLOGICA DE SEMENTES DE JUAZEIRO (Ziziphus joazeiro Marth.) DE DIFERENTES MATRIZES DO SEMIARIDO PARAIBANO
}

\author{
Edjane Oliveira de Lucena ${ }^{1 *}$, Assíria Maria Ferreira da Nóbrega Lúcio ${ }^{1}$, Ivonete Alves Bakke \\ Marllus Adiel Carneiro Pimenta ${ }^{1}$, Talytta Menezes Ramos ${ }^{1}$
}

\begin{abstract}
RESUMO: A Caatinga é um bioma rico em diversidade de plantas e animais e, muitas, com espécies endêmicas relevantes para a região. Sua vegetação é uma das mais exploradas por se tornar fonte de renda para a maioria da população da região nordeste. Dentre as espécies arbóreas presente, destaca-se o Ziziphus joazeiro que possui inúmeras qualidades (forrageira, madeira, medicinal, paisagismo, restauração e recuperação ambiental). O presente estudo objetivou avaliar as variações biométricas e de germinação de sementes de dez matrizes de Zizyphus joazeiro, visando selecionar as matrizes com melhor potencial germinativo para produção de mudas. Avaliou-se a porcentagem de germinação, índice de velocidade de germinação, germinação média diária, comprimento de parte aérea, diâmetro do coleto, comprimento e massa seca e parte aérea das plântulas. O delineamento estatístico utilizado foi o DIC em esquema fatorial. Os dados foram transformados em arc sen $\sqrt{x / 100}$ e as médias comparadas pelo teste de Scott-Knott a $5 \%$ de probabilidade. Verificou-se que existe uma variação genética e ambiental entre as matrizes. Com relação a porcentagem de germinação se destacaram as matrizes $1,2,3$, 4 e 5, em massa seca a matriz 9 , em comprimento e diâmetro de frutos a matriz 1,4 e 10 e, em menor comprimento de sementes as matrizes 5 e 8 .
\end{abstract}

Palavras-chaves: Espécies endêmicas da caatinga, vigor de sementes, qualidade fisiológica de sementes.

\section{BIOMETRICS AND PHYSIOLOGICAL QUALITY OF JUAZEIRO SEEDS (Ziziphus joazeiro Marth.) MATRIX OF DIFFERENT SEMIARID PARAIBA}

\begin{abstract}
The Caatinga is a biome which has a rich diversity of plants and animals and many of these species are endemic. Its vegetation is one of the most exploited because it is a source of income for most of the population of the Northeast. The Ziziphus joazeiro has many qualities. The present study aims to evaluate the biometrical variations and seed germination in ten Zizyphus joazeiro matrices, in order to select the matrices that show better germination potential for seedlings. We evaluated the percentage of germination, rate of germination, daily mean germination, shoot length, diameter, length and root dry weight and dry weight of shoot and the root. The statistical design was a DIC in factorial and means were compared by the Scott-Knott test at 5\% probability and transformed into arcsine. The results show that there is a genetic and environmental variation between the dies. With respect to the percentage of germination, the matrices 1, 2, 3, 4 and 5 were highlighted; matrix 9 in the dry mass; in fruit length and diameter the matrices 1, 4 and 10 were highlighted; and matrices 5 and 8 in smallest length of seed.
\end{abstract}

Key words: Native species, seed vigor, seed physiological quality

\section{INTRODUÇÃO}

A Caatinga é um Bioma que se caracteriza por apresentar riqueza em biodiversidade, endemismos, e é bastante heterogêneo. A maioria dos seus rios permanece a maior parte do ano secos (ALVES, 2007). Para Silva et al. (2004), a vegetação deste bioma apresenta uma fitodiversidade considerável devido a sua elevada quantidade de espécies endêmicas.

Esta região semiárida apresenta um regime pluviométrico irregular com baixos índices. A dormência estabelecida pelo tegumento é uma estratégia benéfica para distribuição da germinação ao longo dos anos resultando com isso a sobrevivência da espécie (FOWLER, BIANCHETTI, 2000).
Sua vegetação é do tipo xerófila, onde a maioria das árvores no período seco, promove a queda foliar, como mecanismo de sobreviver às condições de aridez da região, reduzindo a perda de água pela transpiração.

$\mathrm{O}$ intenso processo de exploração dos seus recursos naturais (lenha, carvão, estacas, entre outros) vem contribuindo na redução da biodiversidade. Portanto, a recuperação destas áreas tem se intensificado nas últimas décadas, necessitando a obtenção de informações destas espécies nativas quanto ao processo germinativo, cultivo e as suas potencialidades para abranger a utilização dos seus recursos (SILVA, 2008).

Segundo a Regra de Análises de Sementes (BRASIL, 1992), existe uma série de prescrições na 
condução de testes de germinação para um grande número de espécies cultivadas, porém, para espécies florestais nativas é necessário selecionar matrizes cujas sementes resultem em mudas uniformes. .

Estudos realizados por Kageyama e Dias (1982), as variações genéticas dentro e entre uma mesma população é a forma mais adequada para determinação das diferenças genéticas dentro de uma mesma população, desde que essas diferenças sejam avaliadas em experimentos laboratoriais, em campo ou viveiros, controlando adequadamente os efeitos ambientais.

A biometria de sementes é uma variável bastante empregada na diferenciação da qualidade fisiológica de diferentes espécies vegetais, sendo que a biometria de frutos e sementes contribui significativamente na diferenciação de espécies de mesmo gênero.

Estudos relatam que sementes que possuem maior tamanho apresentam crescimento de plântulas com taxas mais elevadas, o que gera uma maior probabilidade de sucesso no estabelecimento das plântulas, devido ao maior aproveitamento das reservas realizando um crescimento mais acelerado de raízes e parte aérea.

O Ziziphus joazeiro é uma espécie da família Rhamnaceae, conhecido popularmente como juazeiro. Encontra-se em todo o Nordeste e no norte do Estado de Minas Gerais. Sua copa é frondosa e seus galhos crescem até próximo ao solo (LIMA, 2008). Possui inúmeras qualidades, desde ornamentação, alimentação para os animais (na época da seca, principalmente para caprinos, ovinos e morcegos) e, ainda, proporciona sombra.

É uma espécie pioneira, apresenta-se isolada na vegetação xerófila, floresce de maio a junho e sua regeneração natural sofre com a predação de rebanhos, pois na época de secas é uma das únicas fontes de alimento para estes animais.

Segundo Lorenzi (1992), seus frutos amadurecem de junho a julho. Embora apresente uma grande utilidade, a exploração do Ziziphus joazeiro necessita de conhecimentos que contribuam para seu cultivo, no entanto a dispersão destas unidades apresenta um endocarpo bastante resistente dificultando a produção de mudas em programas de reflorestamento.

Como técnica para quebrar dormência de sementes o ácido sulfúrico tem mostrado bastante eficiência na superação de dormência em sementes de Senna macranthera (Collad.)Irwin et Barn (ESCHIAPATIFERREIRA; PEREZ, 1997), Leucaena diversifolia Schlecht (BERTALOT; NAKAGAWA, 1998), Guazuma ulmifolia Lam (ARAUJO NETO; AGUIAR, 2000), Copaifera langsdorfii Desf (BEZERRA et al., 2002), Bowdichia virgilioides Kunth (SMIDERLE e SOUZA, 2003), Ochroma lagopus Sw (BARBOSA et al., 2004) e de Peltophorum dubium (PIROLI et al., 2005).

Este trabalho objetivou avaliar a variação das características biométricas de sementes e a qualidade fisiológica de sementes de Ziziphus joazeiro de diferentes matrizes, a fim de selecionar as matrizes com melhor potencial germinativo para produção de mudas.

\section{MATERIAL E MÉTODOS}

A área de estudo localiza-se no sitio Cuncas, de propriedade particular, localizada no município de Malta - PB, distante $28 \mathrm{~km}$ da cidade de Patos - PB, situada a $37^{\circ} 17^{\prime}$ longitude oeste e $07^{\circ} 01^{\prime}$ latitude Sul e, com altitude média de $250 \mathrm{~m}$.

O clima é classificado como do tipo BSh segundo a classificação de Koppen, (quente e seco), com precipitação média anual entre 200 e $800 \mathrm{~mm}$, concentrada principalmente nos meses de fevereiro a abril, temperatura média de $29^{\circ} \mathrm{C}$ a $39^{\circ} \mathrm{C}$ (INPE, 2017) com vegetação xerófila.

Foram selecionadas dez matrizes de Ziziphus joazeiro, a uma distância mínima de 100 metros entre elas, baseadas nas características fenotípicas e estado fitossanitário da população. Após a seleção, as matrizes foram georreferênciadas com GPS, onde cada matriz constituiu um lote.

Os frutos maduros foram coletados, acondicionados em sacos de polietileno, etiquetados e conduzidos ao Laboratório de Dendrologia da Unidade Acadêmica de Engenharia Florestal do Centro de Saúde e Tecnologia Rural da Universidade Federal de Campina Grande, Campus de Patos para a instalação do experimento.

Biometria de frutos e sementes: Foram selecionados aleatoriamente 100 frutos de cada matriz para a determinação da biometria (comprimento e diâmetro) através de paquímetro digital com precisão de $0,01 \mathrm{~mm}$. Em seguida estes frutos foram submetidos a fermentação e retirada da mucilagem, depois foram lavados em água corrente sobre peneira de arame, e postos para secar a sombra por 4 dias. Decorrido este período, foi realizado a biometria das sementes.

Após a biometria das sementes, estas foram submetidas a dois tratamentos: ácido sulfúrico a uma concentração de $98,5 \%$ durante 90 minutos e um controle (sem tratamento) submersas em hipoclorito de sódio a $10 \%$, por cinco minutos.

Decorrido esse período, as sementes foram lavadas em água corrente por 5 minutos para a retirada do excesso do ácido e hipoclorito, semeadas em bandejas de polietileno $(26,5 \times 15 \times 4,5) \mathrm{cm}$, no substrato areia lavada e esterilizada em autoclave, e acondicionadas em bancadas na casa de vegetação do Viveiro Florestal da Unidade Acadêmica de Engenharia Florestal. Diariamente foram realizadas contagens do número de sementes germinadas, tendo como critérios de germinação plântulas normais que apresentavam as estruturas essenciais perfeitas (BRASIL, 1992). 
Ao final do teste de germinação (período de 90 dias) foram determinados a porcentagem de germinação (G\%), índice de velocidade de germinação (IVG), germinação média diária (GMD) através das fórmulas abaixo, segundo Maguire (1962) citado por Vieira (1994).

- Porcentagem de germinação (G\%): razão entre o número de sementes germinadas e o número de sementes colocadas para germinar.

$$
\mathrm{G} \%=\mathrm{A} / \mathrm{N} * 100
$$

Onde:

$\mathrm{A}=$ número de sementes germinadas

$\mathrm{N}=$ número de sementes colocadas para germinar

- Índice de velocidade de germinação (IVG): somatório da razão da germinação diária pelo tempo, em dias, decorrido do início do teste.

$$
\mathrm{IVG}=(\mathrm{G} 1 \mathrm{~N} 1)+(\mathrm{G} 2 \backslash \mathrm{N} 2)+\ldots+(\mathrm{Gn} \backslash \mathrm{Nn})
$$

Onde: G1, G2, Gn = número de plântulas normais presentes na primeira contagem, na segunda e última contagem. $\mathrm{N} 1, \mathrm{~N} 2, \mathrm{Nn}=$ número de dias de semeadura à primeira, segunda e última contagem.

Decorridos os 90 dias do teste de germinação, com o objetivo de avaliar a produção de biomassa produzida pela espécie, selecionou-se 10 plântulas de cinco matrizes $1,4,6,7$ e 9 e transplantou-se para tubetes de polietileno, com capacidade de $280 \mathrm{~cm}^{3}$, contendo como substrato esterco bovino e terra de subsolo (1:1). Quinzenalmente, foram avaliadas a altura da parte aérea através de régua milimetrada e diâmetro do coleto com o uso de paquímetro digital.

Decorridos os 60 dias após o transplantio das mudas para tubetes, separou-se com o auxílio de tesoura a parte aérea e as raízes. O material separado foi pesado em balança analítica $(0,0001 \mathrm{~g})$ de precisão e colocado em sacos de papel e levadas à secagem em estufa regulada a $65^{\circ} \mathrm{C} \pm 0,5^{\circ} \mathrm{C}$ até atingir peso constante. Os resultados obtidos foram expressos em gramas por plântula. Foi utilizado o Delineamento experimental Inteiramente Casualizado (DIC) em esquema fatorial de

Tabela 1. Médias para comprimento $(\mathrm{mm})$ e diâmetro $(\mathrm{mm})$ dos frutos e sementes das dez matrizes de Ziziphus joazeiro

\begin{tabular}{ccccc}
\hline Matriz & CF & DF & CS & DS \\
\hline 1 & $17,08 \mathrm{a}$ & $19,32 \mathrm{a}$ & $11,05 \mathrm{~b}$ & $6,76 \mathrm{c}$ \\
2 & $14,76 \mathrm{a}$ & $16,06 \mathrm{c}$ & $10,91 \mathrm{c}$ & $7,16 \mathrm{~b}$ \\
3 & $14,52 \mathrm{~b}$ & $18,50 \mathrm{~b}$ & $10,02 \mathrm{~d}$ & $8,64 \mathrm{a}$ \\
4 & $17,28 \mathrm{a}$ & $19,92 \mathrm{a}$ & $10,71 \mathrm{c}$ & $7,28 \mathrm{~b}$ \\
5 & $13,37 \mathrm{c}$ & $16,19 \mathrm{c}$ & $9,68 \mathrm{e}$ & $6,43 \mathrm{~d}$ \\
6 & $15,33 \mathrm{a}$ & $17,70 \mathrm{~b}$ & $11,05 \mathrm{~b}$ & $7,01 \mathrm{~d}$ \\
7 & $10,64 \mathrm{~d}$ & $11,85 \mathrm{f}$ & $11,23 \mathrm{~b}$ & $5,94 \mathrm{e}$ \\
8 & $9,80 \mathrm{e}$ & $14,35 \mathrm{~d}$ & $9,74 \mathrm{e}$ & $6,92 \mathrm{c}$ \\
9 & $9,15 \mathrm{e}$ & $13,31 \mathrm{e}$ & $10,09 \mathrm{~d}$ & $6,09 \mathrm{e}$ \\
10 & $16,59 \mathrm{a}$ & $18,88 \mathrm{a}$ & $12,14 \mathrm{a}$ & $6,92 \mathrm{c}$ \\
\hline Média & 13,85 & 18,60 & 10,66 & 6,93 \\
CV\% & 4,54 & 3,39 & 1,28 & 2,02 \\
\hline
\end{tabular}

CF: comprimento do fruto, DF: diâmetro do fruto, CS: comprimento da semente, DS: diâmetro da semente.

* Médias seguidas por uma mesma letra não diferem entre si pelo teste Scott-Knott $(\mathrm{P}>0,05)$
$10 \times 2$ (10 matrizes e 2 tratamentos de sementes), com quatro repetições de 25 sementes por tratamento. Os dados foram submetidos à análise de variância e as médias, comparadas pelo teste de Skott Knott a 5\% de probabilidade, utilizando o software ASSISTAT versão 7,6 beta (2012) e transformados em arc sen $\sqrt{x / 100}$.

\section{RESULTADOS E DISCUSSÃO}

Para as variáveis da biometria dos frutos e sementes das dez matrizes de Ziziphus joazeiro foram verificadas diferenças significativas $(\mathrm{p}<0,01)$. As médias estão apresentadas na Tabela 1 .

Os frutos variaram de $9,15 \mathrm{~mm}$ a $17,28 \mathrm{~mm}$ de comprimento e 11,85 a $19,92 \mathrm{~mm}$ de diâmetro e as sementes de $9,68 \mathrm{~mm}$ a $12,14 \mathrm{~mm}$ de comprimento e $5,94 \mathrm{~mm}$ a $8,64 \mathrm{~mm}$ de diâmetro. As matrizes 1,4 e 10 se destacaram com maior comprimento e diâmetro dos frutos. O diâmetro dos frutos obtidos neste trabalho foram inferiores aos encontrados por Silva (2011), cujos valores médios obtidos foram de $16,3 \mathrm{~mm}$ a $17,4 \mathrm{~mm}$.

Resultado semelhante foi encontrado por Santos (2007), com espécie de Tabebuia chrysotrichante. O autor atribuiu esta variação a fatores genéticos e ambientais devido as espécies se localizarem em um ambiente com pouca variação, onde temperatura, precipitação e déficit hídrico elevado atuam nestes parâmetros. O coeficiente de variação foi baixo para comprimento e diâmetro de frutos e sementes, confirmando que a influência ambiental para estas variáveis é menor.

Na maioria das espécies arbóreas há uma enorme variação em relação ao tamanho, número de sementes por fruto e tamanho das sementes, e isto se deve a uma característica da espécie, de forma que os fatores ambientais exercem grande influência sobre a espécie, e quanto a estudos voltados para as variações biométricas, as características de frutos e sementes são de fundamental importância para aumentar a uniformidade, melhoramento da espécie e qualidade destas sementes (CRUZ e CARVALHO, 2003). 
Os fatores abióticos e bióticos influenciam o desenvolvimento das sementes e sua variabilidade genética, isto dentro de uma mesma espécie ou até mesmo dentro de uma mesma planta. Com relação às sementes, as matrizes 5 e 8 foram as que apresentaram sementes de menores tamanhos e para o diâmetro foram as matrizes 7 e 9 .

Foi verificada interação entre os fatores matrizes e métodos de tratamentos de sementes para as variáveis porcentagem de germinação $(\% \mathrm{G})$ e germinação média diárias (GMD) $(\mathrm{P}<0,01)$. A germinação das sementes de Ziziphus joazeiro submetidas à quebra de dormência com ácido sulfúrico iniciou-se aos 28 dias após a semeadura, enquanto as testemunhas (controle) aos 43 dias e se estendendo até 90 dias do teste. Estes resultados dos encontrados por Brito (2008), onde a testemunha iniciou aos 28 dias após a semeadura, e aos 88 dias obteve-se $80 \%$ de germinação.

As diferenças observadas na porcentagem de germinação e na germinação média diária (Tabela 2) podem ser atribuídas às variações genéticas e ambientais das matrizes. Turnbull (1975) citado por Santos (2009), relatam que existe variação dentro de uma mesma espécie devido às influências durante o desenvolvimento das sementes e da variabilidade genética.
No tratamento com ácido sulfúrico as matrizes que apresentaram valores germinativos superiores a $50 \%$ foram a M1(100\%), M2(72,28\%), M3 (88\%), M4 (71,52\%), M5(100\%) e M10 (77,36\%). Enquanto que no tratamento controle foram registradas M2 (100\%), M3 (80\%), M4 (90,16\%), M7 (60,76\%) M9 $(62,12 \%)$ e M10 $(53,52 \%)$.

Sementes de algumas espécies arbóreas nativas com tegumento duro mesmo quando as condições de umidade e temperatura favoráveis resultam em uma baixa porcentagem de germinação (LORENZI, 1992).

Os resultados encontrados neste trabalho são semelhantes aos de Carvalho; Oliveira Filho (1980), que obtiveram uma germinação aos 27,6 dias, entretanto discordam dos encontrados por Lozenri (1992) que obteve 70 a 110 dias para os dois tratamentos propostos respectivamente e, Mendes (1996); Matos (2000) entre 10 a 20 dias. Isto comprova a impermeabilidade do tegumento necessitando de um tratamento para acelerar a germinação.

As matrizes 1 e 5 apresentaram maiores porcentagem de germinação e a matriz 7 foi inferior as demais matrizes para o tratamento ácido sulfúrico, e para o controle a matriz 2 se destacou das demais matrizes.

Tabela 2. Médias de porcentagem de germinação $(\% \mathrm{G})$; índice de velocidade de germinação (IVG) e germinação média diária (GMD) de sementes de dez matrizes de Ziziphus joazeiro.

\begin{tabular}{cccccc}
\hline Matriz/Lote & $\mathbf{C} / \mathbf{T}$ & $\mathbf{\% G}$ & $\mathbf{I V G}$ & \multicolumn{2}{c}{$\mathbf{G M D}$} \\
& & & & $\mathbf{C} / \mathbf{T}$ & $\mathbf{S} / \mathbf{T}$ \\
\hline 1 & $29,48 \mathrm{aA}$ & $11,69 \mathrm{bB}$ & $2,13 \mathrm{a}$ & $4,10 \mathrm{aA}$ & $1,72 \mathrm{bA}$ \\
2 & $18,07 \mathrm{bB}$ & $27,38 \mathrm{aA}$ & $1,38 \mathrm{~b}$ & $1,54 \mathrm{aC}$ & $1,01 \mathrm{aB}$ \\
3 & $22,19 \mathrm{bA}$ & $20,12 \mathrm{aA}$ & $1,48 \mathrm{~b}$ & $2,53 \mathrm{aB}$ & $0,83 \mathrm{bB}$ \\
4 & $17,88 \mathrm{bA}$ & $22,54 \mathrm{aA}$ & $2,68 \mathrm{a}$ & $3,67 \mathrm{aA}$ & $1,80 \mathrm{bA}$ \\
5 & $32,28 \mathrm{aA}$ & $19,00 \mathrm{aB}$ & $2,33 \mathrm{a}$ & $2,90 \mathrm{aB}$ & $1,51 \mathrm{bA}$ \\
6 & $16,22 \mathrm{bA}$ & $7,80 \mathrm{bB}$ & $2,26 \mathrm{a}$ & $2,76 \mathrm{aB}$ & $2,24 \mathrm{bB}$ \\
7 & $06,94 \mathrm{cB}$ & $15,19 \mathrm{bA}$ & $2,23 \mathrm{a}$ & $2,43 \mathrm{aB}$ & $1,71 \mathrm{aA}$ \\
8 & $12,22 \mathrm{cA}$ & $9,89 \mathrm{bA}$ & $2,54 \mathrm{a}$ & $2,99 \mathrm{aB}$ & $1,83 \mathrm{bA}$ \\
9 & $15, \mathrm{bA}$ & $15,53 \mathrm{bA}$ & $3,03 \mathrm{a}$ & $4,61 \mathrm{aA}$ & $2,34 \mathrm{bA}$ \\
10 & $19,34 \mathrm{bA}$ & $13,38 \mathrm{bA}$ & $2,35 \mathrm{a}$ & $2,63 \mathrm{aB}$ & $1,68 \mathrm{bA}$ \\
\hline
\end{tabular}

Colunas - letras minúsculas e linhas - letras maiúsculas. C/T (com tratamento), S/T (Sem tratamento).

Médias seguidas por uma mesma letra não diferem entre si pelo teste Scott-Knott a 5\% de probabilidade

Kageyama e Dias (1982), afirmam que as variações fenotípicas existentes entre populações e dentro de uma mesma população é a forma mais adequada para se determinar estrutura de uma população, de modo que os testes sejam feitos em laboratório, viveiro ou em campo controlando os efeitos ambientais.

A interação mostrou resposta não significativa para o índice de velocidade de germinação (IVG), tendo constatado menores índices nas matrizes 2 e 3 .
Já com relação ao tratamento de sementes o Ácido Sulfùrico mostrou eficiência $(P>0,05)$. .

$\mathrm{Na}$ Tabela 3, os resultados de análise de variância mostraram que das variáveis analisadas, apenas a massa seca de raiz apresentou significância ao nível de $1 \%$ de probabilidade, destacando-se a matriz 9 em produção de biomassa da raiz. Enquanto as matrizes 1,6 e 7 produziram mais biomassa de parte aérea. 
Este fato provavelmente pode ser uma estratégia de defesa da predação e perda de água por transpiração que é maior na parte aérea.

Os valores de altura da plântula variaram de $11,9 \mathrm{~cm}$ a $26,65 \mathrm{~cm}$, e o comprimento de raiz de $19,55 \mathrm{~cm}$ a $22,90 \mathrm{~cm}$ respectivamente.
Os resultados encontrados neste trabalho se aproximam dos valores encontrados em experimento conduzidos por Alves et al (2006), de 26,85 cm para altura de plântulas tratadas com ácido sulfúrico á 90 minutos. Os valores do diâmetro do coleto variaram de 1,67 a $2,10 \mathrm{~mm}$.

Tabela 3. Médias da massa seca de raiz, massa seca de parte aérea, altura da parte aérea, diâmetro e comprimento de raiz, aos 90 dias após semeadura.

\begin{tabular}{cccccc}
\hline Matriz & MSR & MSPA & HPA & DCO & CR \\
\hline 1 & $0.164 \mathrm{~b}$ & $0.498 \mathrm{a}$ & $15.20 \mathrm{a}$ & $2.019 \mathrm{a}$ & $21.40 \mathrm{a}$ \\
4 & $0.095 \mathrm{~b}$ & $0.353 \mathrm{~b}$ & $26.65 \mathrm{a}$ & $1.676 \mathrm{a}$ & $22.25 \mathrm{a}$ \\
6 & $0.144 \mathrm{~b}$ & $0.520 \mathrm{a}$ & $17.70 \mathrm{a}$ & $2.047 \mathrm{a}$ & $22.90 \mathrm{a}$ \\
7 & $0.159 \mathrm{~b}$ & $0.544 \mathrm{a}$ & $17.35 \mathrm{a}$ & $2.102 \mathrm{a}$ & $21.15 \mathrm{a}$ \\
9 & $0.333 \mathrm{a}$ & $0.339 \mathrm{~b}$ & $11.90 \mathrm{a}$ & $1.723 \mathrm{a}$ & $19.55 \mathrm{a}$ \\
\hline
\end{tabular}

MSR: massa seca de raiz, MSPA : massa seca de parte aérea, HPA: altura de parte aérea, DCO: diâmetro do coleto, CR: comprimento de raiz.

Médias seguidas por uma mesma letra, na coluna, não diferem entre si pelo teste Scott-Knott a 5\% de probabilidade

\section{CONCLUSÕES}

Com base nos dados encontrados conclui-se que:

A variação entre as sementes de Zizyphus joazeiro podem ser inerentes aos fatores genéticos das matrizes.

A utilização do ácido sulfúrico na quebra de dormência de Zizyphus joazeiro Mart concentrado por 90 minutos foi eficiente na superação da resistência mecânica imposta pelo tegumento do fruto proporcionando uma germinação mais rápida e uniforme.

\section{REFERÊNCIAS}

ALVES, J. J. A. Geoecologia da Caatinga no semiárido do nordeste brasileiro. Revista Climatologia e Estudos da Paisagem, Rio Claro, v.2, n.1, 2007.

ARAÚJO NETO, J. C.; AGUIAR, I. B. Tratamentos prégerminativos para superar a dormência de sementes de Guazuma ulmifolia Lam. Scientia Forestalis, n.58, p.1524,2000

ASSISTAT Versão 7.6 beta (2011) - Disponível em< http://www.assistat.com> Acessado em: 05/03/2012.

BARBOSA, A. P. et al. Tecnologia alternativa para a quebra de dormência das sementes de pau-de-balsa (Ochroma lagopus Sw., Bombacaceae). Acta Amazônica, v.34, n.1, p.107-110, 2004.

BERTALOT, M. J. A.; NAKAGAWA, J. Superação da dormência em sementes de Leucaena diversifolia
(Schlecht.) Bentham K 1561. Revista Brasileira de Sementes, v.20, n.1, p.39-42, 1998 .

BEZERRA, A. M. C. et al. Germinação e desenvolvimento de plântulas de copaíba em função do tamanho e da imersão da semente em ácido sulfúrico. Revista Ciência Agronômica, v.33, n.2, p.5-12, 2002.

BRASIL. Ministério da Agricultura e Reforma Agrária. Regras para análise de sementes. Brasília: SNDA/DNDV CLAV, 365p. 1992.

BRITO. K. L. M. Influência dos tratamentos físicos e químicos na germinação de Ziziphus joazeiro Mart. (Rhamnaceae). Dissertação apresentada ao Curso de Mestrado em Botânica da Universidade Estadual de Feira de Santana. Revista Magistra, v. 20, n. 1, p. 16-21, 2008.

CRUZ, E.D.; CARVALHO, J.E.U. Biometria de frutos e sementes e germinação de curupixá (Micropholis cf. venulosa. Mart. \& Eichler - Sapotaceae). Acta Amazônica, v.33, n.3, p.389-398, 2003

ESCHIAPATI-FERREIRA, M. S.; PEREZ, S. C. J. G. A. Tratamentos para superar a dormência de sementes de Senna macranthera (Collad.) Irwin et Barn. (Fabaceae Caesalpinoideae). Revista Brasileira de Sementes, v.19, n.2, p.230-236, 1997.

FOWLER, A.J.P.; BIANCHETTI, A. Dormência em sementes florestais. Colombo: Embrapa Florestas, 27p. (Embrapa Florestas. Documentos, 40), 2000.

KAGEYAMA, P. Y. ; DIAS, I. S. Aplicação da genética em espécies florestais nativas. In: CONGRESSO NACIONAL SOBRE ESSÊNCIAS NATIVAS, 5. Campos do Jordão, Anais... p. 782-791. 1982. 
LIMA, Paulo Moisés. Avaliação da atividade de extratos de folhas de Momordica charantia, Auxemma oncocalyx e Ziziphus joazeiro sobre bactérias e larvas de Culex quinquefasciatus. 2008. Dissertação (Mestrado em Ciência Animal) - Universidade Federal Rural do Semiárido, Mossoró-RN, 2008.

LORENZI, H. Árvores brasileiras: manual de identificação e cultivo de plantas arbóreas do Brasil. 2 ed. Instituto Plantarum, Nova Odessa, SP. 1992.

MATOS, F.J.A. Plantas medicinais. Guia de seleção e emprego das plantas usadas na fitoterapia no Nordeste do Brasil. Fortaleza: Edições UFC. 2 ed. 346p. 2000.

MENDES, B.V. Juazeiro (Zizyphus joazeiro Mart.): símbolo da resistência das plantas das caatingas. Mossoró: Fundação Vingt-Um Rosado/ETFERN-UNED, 1996. 24p. (Coleção Mossoroense, 168).

PIROLI, E. L. et al. Germinação de sementes de canafístula Peltophorum dubium (Spreng.) Taub. tratadas para superação da dormência. Colloquium Agrariae, v.1, n.1, p.13-18, 2005.

POPINIGIS, F. Fisiologia da semente. 2. Ed. Brasília: ABRATES, 298p. 1985.

SANTOS, F. S. Biometria, germinação e qualidade fisiológica de sementes de Tabebuia chrysotricha (Mart. Ex A. Dc.) Standl. provenientes de diferentes matrizes. 2007. Dissertação (mestrado) ix, 48 f. ; $28 \mathrm{~cm}$ -
Universidade Estadual Paulista, Faculdade de Ciências Agrárias e Veterinárias, - Jaboticabal, 2007.

SANTOS, F. S.; PAULA, R. C.; SABONARO, D. Z.; VALADARES, J. Biometria e qualidade fisiológica de sememntes de diferentes matrizes de Tabebuia chrysotricha (Mart. Ex DC.) Standl. Scient Forest, v.37, n.82, p.163-173, 2009.

SILVA, J.R.P da. Avaliação dos parâmetros biométricos do fruto de juazeiro (Ziziphus joazeiro Mart.)durante o período de produção. Caderonos de Agroecologia - ISNN 23467934 - Vol. 6, n. 2 dez 2011.

SILVA, J. M. C.; TABARELLI, M.; FONSECA, M. T. ; LINS, L. V. Biodiversidade da caatinga: Ações prioritárias para a conservação. Brasília, DF: Ministério do Meio Ambiente: Universidade Federal de Pernambuco, 2004.

SILVA. R. B. Aspectos ecofisiológicos da germinação de sementes de Arapiraca (Acácia farnesiana (L.) Wild..). 2008. Monografia (Graduação) Curso de Engenharia Florestal. CSTR/UFCG, Patos-PB, 2008.

SMIDERLE, O. J.; SOUSA, R. C. P. Dormência em sementes de paricarana (Bowdichia virgilioides Kunth Fabaceae - Papilionidae). Revista Brasileira de Sementes, v.25, n.1, p.72-75, 2003.

VIEIRA, R.D. Testes de vigor em sementes por Roberval Daiton Vieira e Nelson Moreira de Carvalho. Jaboticabal: FUNEP, 1994. 164p. 